\title{
A inclusão escolar e o movimento Todos Pela Educação'
}

\author{
Morgana Domênica Hattge* \\ Maura Corcini Lopes**
}

\section{Resumo}

Este texto analisa a inclusão a partir de uma das cinco metas previstas em um dos mais profícuos movimentos da sociedade civil brasileira para assegurar que até o ano de 2022 todas as crianças e jovens tenham garantido o direito de acesso à escola básica de qualidade: o Todos Pela Educação, criado em 2006. Partindo de uma perspectiva genealógica no sentido que lhe atribui Michel Foucault, a pesquisa analisa a proveniência e emergência do Movimento no cenário educacional brasileiro neste início de século e suas implicaçôes na política educacional. A referida análise genealógica visibiliza a instauração da performatividade no cenário educacional contemporâneo, entendendo-se esse conceito com base nas teorizações de Stephen Ball. A partir da análise de excertos retirados de publicações de divulgação e de relatórios de monitoramento das metas produzidos pelo Movimento Todos Pela Educação, conclui-se que a inclusão escolar no Movimento assume um caráter de minimização do risco social e que a relação da performatividade com a inclusão se constitui em um paradoxo. Se, por um lado, num sistema escolar pautado pelas exigências da performatividade, a inclusão de todos é uma condição inegociável, absolutamente necessária para reduzir o risco social e elevar o Brasil nos rankings internacionais na Educação, por outro lado, esses ditos "incluídos" ameaçam a performatividade escolar, uma vez que seus desempenhos nas avaliaçôes de larga escala, muitas vezes, não são considerados satisfatórios para atender às metas estabelecidas pelo Movimento Todos Pela Educação.

Palavras-chave: Inclusão; Performatividade; Todos Pela Educação.

\footnotetext{
* Professora doutora do Centro Universitário Univates, Lajeado, Rio Grande do Sul, Brasil. Integrante do Grupo de Estudos e Pesquisa em Inclusão (GEPI/UNISINOS/CNPq).

** Professora doutora da Universidade do Vale do Rio dos Sinos, São Leopoldo, Rio Grande do Sul, Brasil. Coordenadora do Grupo de Estudos e Pesquisa em Inclusão (GEPI/UNISINOS/CNPq).
} 


\section{School inclusion and "All For Education" movement}

\section{Abstract}

This paper analyzes inclusion by considering one of the five goals established by one of the most fruitful movements of the Brazilian civil society to guarantee that every child and youth have access to good quality education by 2022: the "All for Education" Movement, created in 2006. From a genealogical perspective as proposed by Michel Foucault, the research analyzes both the provenience and emergence of the Movement in the Brazilian educational scenario early in this century and its implications on educational policies. Performativity, a concept here understood according to Stephen Ball's theorizations, has been established in the contemporary educational scenario, as the genealogical analysis has shown. By analyzing excerpts from publications and reports monitoring the goals set by the "All for Education" Movement, we have concluded that school inclusion has taken on the function of minimizing social risk, and the relationship between performativity and inclusion has become a paradox. On the one hand, in a school system grounded on performativity requirements, the inclusion of all is not negotiable and is absolutely necessary to reduce social risk and improve Brazil's position in international education rankings; on the other hand, those who are "included" threaten the school performativity, since their performances in large-scale evaluations are often regarded as too poor to meet the goals set by the "All for Education" Movement.

Keywords: Inclusion; Performativity; All for Education.

Na política educacional brasileira, a discussão da inclusão escolar ficou, por muito tempo, estreitamente vinculada às discussóes da Educação Especial e desse modo, suas práticas costumam ainda, muitas vezes, incidir especialmente sobre os sujeitos com deficiência ou aqueles considerados com "necessidades educativas especiais". De forma mais abrangente, no presente artigo, propóe-se discutir a inclusão como uma invenção de nosso tempo (LOPES, FABRIS, 2013). Uma invenção que abarca pessoas com deficiência e todos aqueles que são histórica e negativamente discriminados no Brasil. Diante de uma profusão de políticas de inclusão e de inúmeros investimentos governamentais, feitos ao longo da década de 2000 até meados da década de 2010, propóe-se problematizar um dos mais profícuos movimentos da sociedade civil brasileira para assegurar que até o ano de 2022 todas as crianças e jovens tenham garantido o direito de acesso à escola básica de qualidade: o Todos Pela Educação (TPE), criado em 2006. O Movimento visa contribuir para que todos os alunos estejam "efetivamente aprendendo na Pré-Escola ( 4 a 5 anos), no Ensino Fundamental (6 a 14 anos) e no Ensino Médio (15 a 17 anos)." (TODOS PELA EDUCAÇÃO, 2011, p. 11).

Decorrente de uma pesquisa maior, a discussão feita neste texto foca a inclusão a partir de uma das cinco metas previstas no movimento TPE, qual seja: "Meta 1 Toda criança e jovem de 4 a 17 anos na escola". As demais metas seráo explicitadas no 
primeiro subtítulo, mas não serão desenvolvidas aqui. Para problematizar o caráter includente da primeira meta, serão utilizados conceitos-ferramenta importantes tanto para tecer a grade de inteligibilidade da governamentalidade neoliberal, sobre a qual a inclusão se inscreve, quanto para fornecer elementos que permitam compreender a noção de risco social e de performatividade, ambas articuladas às práticas no campo da educação e à inclusão.

A partir da análise de excertos retirados de publicaçôes de divulgação e de relatórios de monitoramento das metas produzidos pelo movimento Todos Pela Educação conclui-se que a inclusão escolar no movimento Todos Pela Educação assume um caráter de minimizaçáo do risco social e a relação da performatividade com a inclusão constitui-se em um paradoxo. Tal argumento será melhor discutido no decorrer do artigo.

Assim, o texto está dividido em três subtítulos. No primeiro deles intitulado "Todos Pela Educação: a grade de inteligibilidade neoliberal e a noção de risco social", são apresentadas condiçôes de proveniência e emergência do TPE, as implicaçôes que se pode perceber entre o movimento Todos Pela Educaçáo e a política educacional no contexto mais amplo de uma grade de inteligibilidade neoliberal e a forma como o Movimento opera na minimização do risco social. O segundo subtítulo, intitulado "Performatividade e Movimento Todos Pela Educação" pretende mostrar de que forma a performatividade se institui no cenário educacional contemporâneo, entendendo-se esse conceito a partir das teorizaçóes de Stephen Ball. Por fim, no subtítulo "A inclusão como paradoxo em sua relação com a performatividade" discute-se de que forma os conceitos de inclusão e performatividade se articulam no movimento Todos Pela Educação.

\section{Todos pela educação: proveniência e emergência do movimento em um contexto neoliberal}

Lançando-se para o TPE um olhar genealógico foi possível visibilizar a proveniência e a emergência do Movimento e suas implicaçôes com o cenário político contemporâneo. Na pesquisa genealógica cunhada por Foucault (2002), e inspirada em Nietzsche, realizam-se dois movimentos de análise que se complementam: a pesquisa de proveniência e a pesquisa de emergência. Na pesquisa de proveniência é preciso analisar "a proliferação dos acontecimentos através dos quais (graças aos quais, contra os quais) eles se formaram" (FOUCAULT, 2002, p. 20-21). Trata-se de uma busca pelas bases políticas, sociais, que possibilitaram arranjos específicos que dão o solo no qual um determinado acontecimento pode ir criando contornos próprios. Já a pesquisa de emergência seria "o ponto de surgimento no passado, cuidando para que não se coloque nesse passado, um conceito, uma idéia ou um entendimento que é do presente" (VEIGA-NETO, 2003, p. 71-72). "A emergência se produz sempre em um determinado estado de forças" (FOUCAULT, 2002, p. 23) em que determinado acontecimento irrompe.

Assim, a análise dos materiais do Movimento permite-nos afirmar que o TPE tem sua proveniência relacionada à proliferação discursiva em torno da necessidade 
de reforma educacional, alinhada às políticas de educação para todos, táo naturalizadas na atualidade. Essa articulação relaciona-se intimamente com um cenário instituído no interior de uma grade de inteligibilidade neoliberal, que a continuidade do texto procura visibilizar.

O discurso da reforma educacional já pode ser percebido no movimento da Escola Nova, em meados da década de 1930 (há quase um século atrás). O manifesto não propóe mudanças somente relacionadas à política e à administração da educação, por isso podemos classificá-lo como um movimento em que já está presente o gérmen do discurso contemporâneo da reforma educacional. Um dos pilares da proposta da Educação Nova é a ênfase em princípios científicos sobre os quais a educação deve apoiar-se para que se busque o desenvolvimento integral do indivíduo. $\mathrm{O}$ aluno como um sujeito de interesses é o foco do processo educativo.

Ao tratar da questão do liberalismo, Foucault (2008) salienta que na base dessa nova razão governamental que passa a se instituir no início do século XVIII e que tem como princípio fundamental a autolimitação, é central a noção de "interesse" (FOUCAULT, 2008).

Partindo-se de dois entendimentos heterogêneos do conceito de liberdade, a saber, a liberdade como "exercício de certo número de direitos fundamentais" (FOUCAULT, 2008, p. 57) e como "independência dos governados em relação aos governantes" (FOUCAULT, 2008, p. 57), admite-se a busca de "conexôes possíveis entre termos díspares e que permanecem díspares" (FOUCAULT, 2008, p. 57). "É essa ambiguidade que caracteriza, digamos, o liberalismo europeu do século XIX e também do século XX" (FOUCAULT, 2008, p. 58). Mas essa ambiguidade encontra seu ponto de intersecção na já referida noção de interesse. E muito para além de instituir "liberdades", Foucault (2008) argumenta que essa arte de governar liberal será consumidora de liberdade. Porém, essa liberdade precisa ser regulada pelo princípio da segurança, já que pode ser necessário, dentro desse regime de fabricaçáo das liberdades, "proteger o interesse coletivo contra os interesses individuais. Inversamente, a mesma coisa: será necessário proteger os interesses individuais contra tudo o que puder se revelar, em relação a eles, como um abuso vindo do interesse coletivo" (FOUCAULT, 2008, p. 89). Em meio a esse contexto os signatários do movimento pela Escola Nova propóem uma nova organização de política e administração educacional.

Porém, se, no referido movimento da Escola Nova, em meio ao contexto do liberalismo, a reforma educacional deveria se dar no sentido de popularizar a escola, democratizar o acesso e trazer para a escola essa relação entre liberdade e segurança, neste início do século XXI, em meio a uma grade de inteligibilidade neoliberal as lutas se dão em outros sentidos.

Foucault (2008) ao estudar a passagem do liberalismo ao neoliberalismo, utiliza como chave de análise do modelo neoliberal norte-americano a Teoria do Capital Humano, desenvolvida na década de 1950 por teóricos da Escola de Chicago, entre eles Theodore Schultz e Gary Becker. Procedendo a uma decomposição do trabalho em capital e renda, o trabalhador passa a ser "ele próprio seu capital, sendo para si 
mesmo seu produtor, sendo para si mesmo a fonte de [sua] renda" (FOUCAULT, 2008, p. 311). Portanto, se o capital passa a ser a competência do sujeito, é preciso investir nesse capital. Dessa forma, educação passa a ser vista como um investimento. Um investimento necessário para o acúmulo de capital humano. Desse modo, essa educação escolarizada, que deve investir em capital humano, passa a se constituir em uma preocupação cada vez maior em diferentes áreas como a economia e a administração.

Individualismo e competitividade são palavras-chave para a compreensão dessa governamentalidade neoliberal em que "as habilidades e as aptidóes de um indivíduo qualquer constituem, elas mesmas, pelo menos virtualmente e relativamente independente da classe social a que ele pertence, seu capital" (GADELHA, 2009, p. 149). Para o projeto neoliberal, todos devem ter condiçôes de participação no jogo econômico e de mercado.

Assim, "desde 1945 a ideia de desenvolvimento será fundamental e é a partir dela que se dará tanto a análise dos países ditos desenvolvidos quanto o controle e a vigilância dos países considerados a partir de então subdesenvolvidos" (KLAUS, 2011, p. 99). Dessa forma, com o objetivo, entre outros, de impulsionar o desenvolvimento dos países considerados subdesenvolvidos, são criados os organismos internacionais, como a Organização das Nações Unidas (ONU), fundada em 1945 e ligado à ONU, o Banco Mundial (BM), um dos grandes responsáveis pela indicação de reformas educacionais nos países considerados subdesenvolvidos.

Entendemos que é neste momento que se pode perceber uma proliferação do discurso da reforma educacional, que vai se fortalecer, mais especificamente, nas décadas de 1980 e 1990, quando se vê uma atuação bastante incisiva do Banco Mundial na proposição de reformas educacionais para os países em vias de desenvolvimento, como passaram a ser chamados os antes considerados países subdesenvolvidos. Assim, o Banco Mundial impóe uma série de condicionalidades aos países, entre elas, as reformas na área da educação.

No caso do Brasil, é possível afirmar que a agenda educacional brasileira vem sendo, em grande parte, desde a década de 1990, fortemente interpelada pelo discurso da reforma educacional. Portanto, é nesse cenário constituído no interior de uma grade de inteligibilidade neoliberal, na qual a participação de todos nos jogos de mercado e a necessidade de desenvolvimento justificam os esforços pela educação para todos e por reformas educacionais que venham a dar conta das demandas de investimento em Capital Humano, que se dá a proveniência do movimento Todos Pela Educação.

Já a sua emergência se justifica a partir de três fatores: a necessidade de um sistema educacional capaz de conduzir o país rumo ao desenvolvimento, a constataçáo de uma crise política que demandava uma mobilizaçáo social em prol da construção de valores que somente se poderia concretizar através da educação e a constatação da incompetência dos responsáveis pela gestão da educação no país. 
Assim, para atingir seus objetivos, o Movimento estrutura-se em torno de 5 metas consideradas por seus idealizadores ${ }^{2}$ como facilmente verificáveis e mensuráveis:

$$
\begin{aligned}
& \text { Meta } 1 \text { - Toda criança e jovem de } 4 \text { a } 17 \text { anos na escola } \\
& \text { Meta } 2 \text { - Toda criança plenamente alfabetizada até os } 8 \text { anos } \\
& \text { Meta } 3 \text { - Todo aluno com aprendizado adequado à sua série } \\
& \text { Meta } 4 \text { - Todo aluno com Ensino Médio concluído até os } 19 \text { anos } \\
& \text { Meta } 5 \text { - Investimento em Educação ampliado e bem gerido. } \\
& \text { (TODOS PELA EDUCAÇÃO, 2009, p. 18). }
\end{aligned}
$$

A meta 1 é aquela que trata da questão da inclusão escolar. Percebe-se que, no movimento Todos Pela Educação, a inclusão escolar é uma questão de risco social. Embora não apresente a questão de forma explícita, indiretamente a questão do risco social é referida nos documentos analisados, através da relação que o Movimento estabelece entre educaçáo e desenvolvimento e entre educação e desenvolvimento humano, como é possível perceber no excerto selecionado.

Uma sociedade com maior escolaridade média está associada a saúde melhor, menores índices de violência, melhor renda e maiores taxas de crescimento econômico. No entanto, o atendimento escolar ainda traz desafios. (TODOS PELA EDUCAÇÃO, 2008, p. 11).

De acordo com Spink (2001, p. 1279), a noção de risco foi criada "na transição entre a sociedade feudal e as novas formas de territorialidade que dariam origem aos Estados Naçáa”. Segundo a autora era comum que a humanidade enfrentasse perigos diversos, no que diz respeito às catástrofes naturais ou às guerras, ou ainda aqueles perigos relacionados à vida cotidiana. Porém, esses eventos não eram chamados de riscos. Eram considerados perigos, uma vez que a palavra risco sequer existia. A palavra foi criada para dizer da possibilidade de ocorrência de eventos em uma sociedade que acreditava poder, até certo ponto, controlar o futuro. $\mathrm{O}$ risco diz respeito a eventos sociais que podem ser mensurados, calculados, e em certa medida, previstos. "O conceito de risco envolve a sofisticação da estatística e seu uso como ciência de estado" (SPINK, 2001, p. 1280). E se acreditamos poder prever, mensurar esses riscos, também acreditamos que seja possível administrá-los, geri-los, minimizando seus efeitos. Nesse sentido, as políticas de inclusão escolar, são exemplos de diferentes tecnologias colocadas em funcionamento para a redução do risco social relacionado à população em idade escolar, uma vez que

[...] além de facilitar a vigilância, ao incluírem-se os alunos, trazendo-os para mais perto, onde 'a vista os alcança!', também barateamos custos para o Estado. [...] Dessa forma, são gerenciadas, ao mesmo tempo, comunidades, famílias e indivíduos, evitando-se uma série de riscos, levando a uma economia da máquina estatal. (HATTGE, 2007, p. 194). 
Alinhada a esse sentido de redução do risco social, a concepção de inclusão escolar apresentada pelo Movimento distancia-se de uma concepção estritamente relacionada ao campo da Educação Especial - embora essa relação não desapareça de todo -, que diz respeito à inserção de alunos com deficiência ou com necessidades educacionais especiais nas escolas regulares, demonstrando esse alargamento do próprio conceito de inclusão. Retomaremos essa discussão na última seção do texto.

\title{
Performatividade e Movimento Todos Pela Educação
}

Tomaremos neste texto a noçáo de performatividade no sentido que lhe atribui o pesquisador Stephen Ball (2002; 2004; 2010), relacionando-se o termo a um sentido de produtividade, de auferição de resultados que possam ser mensurados e quantificados.

\begin{abstract}
A performatividade é uma tecnologia, uma cultura e um modo de regulação que se serve de críticas, comparações e exposições como meios de controlo, atrito e mudança. Os desempenhos (de sujeitos individuais ou organizaçóes) servem como medidas de produtividade e rendimento, ou mostras de "qualidade" ou ainda "momentos" de promoção ou inspeção. Significam, englobam e representam a validade, a qualidade ou valor de um indivíduo ou organizaçáo dentro de um determinado âmbito de julgamento/ avaliação. (BALL, 2002, p. 4).
\end{abstract}

Nas reformas educacionais levadas a cabo na educação básica, as tecnologias colocadas em funcionamento por meio da gestão da escola, como a cultura de metas, a meritocracia, a visibilidade dos indicadores de desempenho dos sujeitos e das organizaçôes, trazem impactos profundos e instituem novas formas de regulação das condutas. Entendemos que, para além disso, essas tecnologias colocadas em ação, ao produzirem novas formas de governamento, dentro de uma grade de inteligibilidade neoliberal, de supervalorizaçáo da competitividade e da responsabilização, nos constituem a todos. "Num sistema que tem a performatividade por base, o que interessa são os resultados, os indicadores de desempenho" (BUJES, 2012, p. 167). Não somente professores, mas alunos, famílias e a sociedade em geral que vem sendo convocada a assumir sua responsabilidade pela qualidade da educaçáo e consequente desenvolvimento de toda a nação.

Entendemos que a performatividade vem articulada ao capital humano; ela só pode se desenvolver através dele. Portanto, nessa grade de inteligibilidade neoliberal a performatividade passa a regular os sujeitos e as instituições funcionando por meio do investimento em capital humano. E essa regulação e esse investimento somente são possíveis se todos estiverem incluídos nessa racionalidade.

A operação da performatividade no movimento Todos Pela Educação depende de duas condiçóes fundamentais: em primeiro lugar, para que o país avance na qualidade da educação, que se traduz, para o Todos Pela Educaçáo, em melhores desempenhos nos rankings internacionais de avaliação da aprendizagem escolar, é necessária a inclusão de todos no sistema educacional. Por esse motivo o Todos Pela 
Educação investe de forma massiva na sua Meta 1, que é a meta que materializa o esforço pela inclusão. Em segundo lugar, para que seja possível perseguir o alcance de metas educacionais "claras, mensuráveis e efetivas" (TODOS PELA EDUCAÇÃO, 2011, p. 11) é necessário que a aprendizagem se reconfigure e passe a ser entendida como desempenho. Desse modo, no momento em que todos estiverem na escola será possível investir esforços na melhoria da aprendizagem, que deve ser "medida" através das avaliaçóes de larga escala que serão capazes de mostrar o avanço do país na sua comparação com ele mesmo (na análise de séries históricas de desempenhos nas avaliaçôes nacionais) e com outros países (no avanço de posiçóes nos rankings internacionais).

Então é possível dizer que para a operação da performatividade é necessária uma articulação entre performatividade, inclusão e reconfiguração da aprendizagem. Só é possível investir no capital humano (aprendizagem) desses sujeitos que se encontram incluídos nessas práticas. Porém, importa perguntar: que relação se pode perceber entre a inclusão e a performatividade? De que forma esses dois conceitos se articulam no movimento Todos Pela Educação?

\section{A inclusão como paradoxo em sua relação com a performatividade}

Atualmente as políticas de inclusão incidem sobre diferentes segmentos da população (pobres, negros, indígenas, mulheres, homossexuais etc.). No limite, todos somos alvo das políticas de inclusão, pois estar incluído é um imperativo. Para a governamentalidade neoliberal

$$
\begin{aligned}
& \text { [...] na Contemporaneidade, a inclusão ocupa um lugar de impera- } \\
& \text { tivo de Estado. Imperativo porque o Estado toma a inclusão como } \\
& \text { um princípio categórico que, por ser evidente em si mesmo, é im- } \\
& \text { posto de formas diferenciadas e de acordo com hierarquias de parti- } \\
& \text { cipação, a todas as formas de vida, sem exceção. Garantir para cada } \\
& \text { indivíduo uma condiçáo econômica, escolar e de saúde, compatível } \\
& \text { com seu nível e sua rede de relações, pressupóe fazer investimentos } \\
& \text { para que a situação presente de pobreza absoluta, de falta de educa- } \\
& \text { ção básica e de saúde, talvez se modifique em curto e médio prazos. } \\
& \text { (LOPES; LOCKMANN; HATTGE; KLAUS 2010, p. 6-7). }
\end{aligned}
$$

É claro que essa inclusão de todos se dá em diferentes "níveis de participação ou gradientes de inclusão", uma vez que as formas de acesso, as possibilidades de interação não são as mesmas para todos. Por esse motivo, preferimos utilizar o conceito de "in/exclusão" (LOPES; FABRIS, 2013, p. 8), uma vez que "diante de tal participação por gradientes de inclusão [...] qualquer sujeito, dentro de 'seu nível de participação' poderá, a todo o momento, estar incluído ou ser excluído de determinadas práticas, açôes, espaços e políticas" (LOPES; LOCKMANN; HATTGE; KLAUS 2010, p. 5-6).

Nos materiais do TPE, é possível vislumbrar, nas análises dos dados preliminares acerca do cumprimento da Meta 1, que são observadas as categorias de gênero, 
cor, região de moradia e rendimento familiar per capita. Essa concepção de inclusão escolar está bastante alinhada a essa forma de se compreender a inclusão como um imperativo do nosso tempo, fundado em uma governamentalidade neoliberal. Menezes (2011) percebe que a sociedade assume hoje

[...] um compromisso coletivo, portanto, com a inclusão de todos nas práticas escolares, que, agenciadas com o Estado, produzem como efeito a constituição de subjetividades inclusivas - subjetividades que precisam ser ensinadas a se autogestar em busca da sua condição de inclusão. (MENEZES, 2011, p. 133).

Assim, os esforços empreendidos em torno da meta 1vão incidir sobre toda a populaçáo em idade escolar, ou seja, toda a criança ou jovem que tem entre 4 e 17 anos. Há tempos atrás a atenção estava voltada aos alunos do Ensino Fundamental. Hoje a ação do Estado se estende a uma gama maior de sujeitos buscando garantir uma formaçáo que possibilite a cada um manter-se no jogo de mercado instaurado pela governamentalidade neoliberal.

$\mathrm{Na}$ atualidade, todos devem fazer parte do jogo neoliberal, ou seja, ninguém deve ser deixado de fora. Isso se dá porque o neoliberalismo necessita da circulação e da mobilidade dos indivíduos de forma que a sua máxima é a inclusão do maior número de pessoas nas malhas do poder. Porém, a mobilidade de um indivíduo na atualidade está diretamente relacionada com um empreendimento de si mesmo com investimento e renda - sujeito empresário de si mesmo. (LOPES; LOCKMANN; HATTGE; KLAUS, 2010, p. 24).

Daí se justifica a importância do monitoramento estatístico da inclusão escolar de toda uma gama de especificidades referidas anteriormente. Uma das principais preocupaçôes do TPE é que por meio da inclusão de todas as crianças e jovens seja possível alavancar o desenvolvimento do país.

Análise socioeconômica

Embora nos últimos anos os índices de desigualdade do Brasil tenham diminuído, nosso país ainda é considerado um dos mais desiguais. Segundo dados do Banco Mundial, entre 2001 e 2010, o índice de Gini, que mede a desigualdade entre os mais ricos e os mais pobres da populaçáo - no qual 0 é igualdade perfeita e 1 é a total desigualdade entre os indivíduos -, teve uma melhora de 0,586 para 0,550 , no Brasil.Estudos apontam que a diminuição das diferenças sociais se torna permanente por meio da maior igualdade de acesso a oportunidades de desenvolvimento humano, e a Educação é uma das grandes responsáveis por isso. (TODOS PELA EDUCAÇÃO, 2010, p. 16-22).

Nesse sentido, faz-se necessário um cuidado para que todos os grupos dos ditos "excluídos" sejam monitorados e inseridos no sistema educacional. 
A Meta 1 só será cumprida se os resultados incluírem não apenas todas as faixas etárias como também todos os indivíduos. Por isso, uma análise do entendimento escolar para diferentes recortes demográficos é bastante útil. $\mathrm{O}$ primeiro recorte a ser estudado é o de gênero. Ao longo do tempo, a inclusão das mulheres no mercado de trabalho teve uma consequência bastante positiva em termos de Educação: as meninas passaram a estudar mais. (TODOS PELA EDUCAÇÃO, 2010, p. 19).

A inclusão, nesse caso, consiste em uma estratégia biopolítica de governamento dos sujeitos de forma que a inclusão escolar seja um primeiro passo na constituição de sujeitos empreendedores e empresários de si mesmos. O que se busca é atingir a totalidade da população em idade escolar, com o objetivo de garantir a seguridade social, por meio do monitoramento de uma série de dados estatísticos que permitem mensurar a evolução da inclusão na educação básica no Brasil. Novamente, a inclusão das crianças, no espaço da escola, trabalha no controle do risco social.

Para que a escola possa operar nessa racionalidade como espaço produtivo, precisa assumir e desempenhar algumas açóes que a posicionem como uma instituição que, além da normação disciplinar, precisa operar no eixo da normalizaçáo própria de uma sociedade de seguridade, isto é, produzir açóes para reduzir ou eliminar os riscos sociais. Quais os riscos sociais que a escola pode reduzir ou eliminar? (FABRIS; TRAVERSINI, 2013, p. 39).

Para o movimento Todos Pela Educação, a resposta à questão formulada pelas pesquisadoras relaciona-se ao excerto abaixo:

A primeira meta é também o primeiro passo da caminhada que deverá nos levar ao sistema educacional que queremos: toda criança e jovem de 4 a 17 anos freqüentando a escola. Complementarmente ao ambiente familiar, uma boa escola é responsável por formar cidadãos pois, além do conteúdo formal que nela deve ser adquirido, estimula-se ali o convívio social, a criatividade e o senso crítico, entre outras habilidades. Sabe-se que mais Educação tem efeitos positivos para os individuos que a adquirem e para a sociedade em que convivem. Uma sociedade com maior escolaridade média está associada a saúde melhor, menores indices de violência, melhor renda média e maiores taxas de crescimento econômico. No entanto, o atendimento escolar ainda traz desafios. (TODOS PELA EDUCAÇĀO, 2008, p. 11).

Os excertos anteriores nos remetem à relação que se estabelece entre educação e desenvolvimento, que está na base das políticas de educação para todos e ainda, por que não dizer, na base da instituição da performatividade na educação. Assim, o que se percebe na análise das publicações do TPE é que em sua relação com a performatividade a inclusão se constitui em um paradoxo. Se por um lado, num sistema escolar pautado pelas exigências da performatividade, a inclusão de todos é uma condição 
inegociável, absolutamente necessária para a operação da performatividade, por outro lado esses ditos "incluídos" ameaçam a performatividade escolar, uma vez que seus desempenhos nas avaliaçóes de larga escala, muitas vezes, não são considerados satisfatórios para atender às metas estabelecidas de antemão.

Esse é o paradoxo. Para que a performatividade entre em ação, todos devem estar incluídos. Estando todos incluídos, a performance do todo pode sofrer impactos negativos em função da baixa performance de alguns. E geralmente, quem são aqueles que apresentam essa baixa performance? Aqueles a quem se entende que sejam dirigidas de forma mais incisiva hoje as políticas de inclusão escolar, ou seja, em especial as pessoas com deficiência, as mulheres, negros e os mais pobres, por exemplo.

Embora, no sentido dicionarizado, as palavras contradição e paradoxo sejam utilizadas, muitas vezes, como sinônimos, justifico minha escolha por uma delas em detrimento da outra através da sua constituição semântica. Enquanto a primeira delas inicia-se com o sufixo "contra", que dá a ideia de oposição, a segunda tem em sua constituição o prefixo "para", que traz em si a ideia de proximidade.

[...] em grego a raiz * dek perdurou no verbo dokéo, que deu lugar a dogma [...] e dóksa, este último termo de amplas ressonâncias filosóficas, significa 'opiniáo', 'crença' - geralmente por oposição ao certame verdadeiro. Ainda que dóksa não se tenha conservado em português, a não ser como recorrência técnica do jargão acadêmico, são variados os compostos a que deu lugar. Assim, por exemplo, 'heterodoxia', 'de crença diferente'; 'ortodoxia', 'crença reta ou correta' e 'paradoxo', 'o que está junto à dóksa', 'o que corre em paralelo' e, portanto, é alheio e aparentemente incompatível com ela, com os prefixos héteros, 'diferente'; 'orthós', 'reto' e 'pará, 'junto a'. (CASTELLO; MÁRSICO, 2007, p. 59-60).

Dessa forma, sublinhamos a partir da análise da construção da palavra exposta acima, que nâo entendemos que a performatividade e a inclusão guardem entre si uma relação de contradição, pois não se trata de uma simples "oposição". Trata-se de que a inclusão precisa estar "junto à" performatividade, pois sem a inclusão a performatividade não se efetiva, mas paralelamente a isso ela coloca em risco as metas estabelecidas pela performatividade na área da educação. Dessa forma, "correndo em paralelo" a inclusão e a performatividade colocam em ação diferentes estratégias que geralmente "não se encontram", não "conversam" e instituem políticas educacionais que tornam-se de difícil efetivação. Analisar os contextos de produção dessas políticas, sua gênese e seus efeitos pode nos ajudar a repensar esses processos e vislumbrar a possibilidade de criação de outros processos de inclusão, pautadas em outros princípios, mais condizentes com um projeto que se diz para todos. 


\section{Referências}

BALL, S. J. Reformar escolas, reformar professores e os terrores da performatividade. Revista Portuguesa de Educaçáo, Braga, Portugal, a./v. 15, n. 002, p. 3-23, 2002.

Performatividade, privatização e o pós-estado do bem-estar. Revista Educaçáo e Sociedade, Campinas, v. 25, n. 89, p. 1105-1126, set./dez., 2004.

Performatividades e Fabricações na Economia Educacional: rumo a uma sociedade performativa. Revista Educaçáo e Realidade, Porto Alegre, v. 35, n. 2, p. 37-55, mai./ago., 2010.

BUJES, M. I. E. Cultura da performatividade, expertise e os desencaixes da escola contemporânea. In: SARAIVA, K.; MARCELLO, F. de A. (Orgs.). Estudos Culturais e Educaçáo: desafios atuais. Canoas: Ed. da ULBRA, 2012. p. 157-171.

CASTELLO, L. A.; MÁRSICO, C. T. Oculto nas palavras: dicionário etimológico para ensinar e aprender. Tradução de Ingrid Müller Xavier. Belo Horizonte: Autêntica, 2007.

FABRIS, E. T. H.; TRAVERSINI, C. S. Conhecimentos escolares sob outras configuraçóes: efeitos das movimentaçôes disciplinares e de controle? In: TRAVERSINI, C. S.; DALLA ZEN, M. I. H.; FABRIS, E. T. H.; DAL'IGNA, M. C. (Orgs.). Currículo e Inclusão na escola de ensino fundamental. Porto Alegre: EDIPUCRS, 2013. p. 34-53.

FOUCAULT, M. Microfísica do Poder. 17. ed. Rio de Janeiro: Ediçóes Graal, 2002.

Nascimento da biopolítica. São Paulo: Martins Fontes, 2008.

GADELHA, S. Biopolítica, governamentalidade e educaçáo. Introduçôes e conexôes, a partir de Michel Foucault. Belo Horizonte: Autêntica Editora, 2009.

HATTGE, M. D. A gestão da inclusão na escola: estratégia de controle do risco social. In: LOPES, M. C.; DALIGNA, M. C. (Orgs.). In/exclusão: nas tramas da escola. Canoas: Ed. ULBRA, 2007. p. 189-200.

KLAUS, V. Desenvolvimento e governamentalidade (neo)liberal: da administraçáo à gestão educacional. Tese (Doutorado em Educação) - Programa de Pós-Graduação em Educação, Faculdade de Educação, Universidade Federal do Rio Grande do Sul, Porto Alegre, 2011.

LOPES, M. C.; FABRIS, E. H. Inclusão \& Educação. Belo Horizonte: Autêntica, 2013.

LOPES, M. C.; LOCKMANN, K.; HATTGE, M. D.; KLAUS, V. Inclusáo e Biopolítica. Cadernos IHU Ideias, Unisinos, a. 8, n. 144, 2010.

MENEZES, E. C. P. A maquinaria escolar na produçáo de subjetividades para uma sociedade inclusiva. Tese (Doutorado em Educaçấo) - Programa de Pós-Graduação em Educação. Universidade do Vale do Rio dos Sinos, São Leopoldo, RS, 2011.

SPINK, M. J. Trópicos do discurso sobre risco: risco-aventura como metáfora da modernidade tardia. Cad. Saúde Pública, Rio de Janeiro, v. 17, n. 2, nov./dez., 2001, p. 1277-1311.

TODOS PELA EDUCAÇÃO. De Olho nas Metas. Primeiro relatório de acompanhamento das 5 Metas do movimento Todos Pela Educação. São Paulo: Todos Pela Educação, 2008, 132 pp.

Todos Pela Educaçáo 2006-2009. São Paulo: Todos Pela Educação, 2009, 57 pp.

De Olho nas Metas 2010. Terceiro relatório de acompanhamento das Metas do movimento Todos Pela Educação. São Paulo: Todos Pela Educação, 2010, 162 pp.

Todos Pela Educação. 5 anos, 5 metas, 5 bandeiras. São Paulo: Todos Pela Educação, 2011, 119 pp.

VEIGA-NETO, A. Foucault \& a Educaçáo. Belo Horizonte: Autêntica, 2003.

\section{Notas}

${ }^{1}$ Financiamento Capes.

${ }^{2} \mathrm{O}$ movimento Todos Pela Educação foi idealizado por um grupo de empresários e representantes do poder público ao qual se uniram intelectuais e outros membros da sociedade civil. 


\section{Correspondência}

Morgana Domênica Hattge - Centro Universitário Univates, Curso de Pedagogia. Av. Avelino Tallini, 171, Universitário. CEP: 95900-000. Lajeado, Rio Grande do Sul - Brasil.

E-mail:mdhattge@univates.br-maurac@terra.com.br

Recebido em 17 de junho de 2015

Aprovado em 06 de agosto de 2015 